\title{
钴催化的环丙烯不对称氢烷基化反应
}

\author{
何 斌 ${ }^{a}$ 钮大文*,a,b \\ $\left({ }^{a}\right.$ 四川大学华西医院 成都 610041) \\ $\left({ }^{b}\right.$ 四川大学化学工程学院 成都 610041)
}

\section{Cobalt-Catalyzed Asymmetric Hydroalkylation of Cyclopropenes}

\author{
$\mathrm{He}, \operatorname{Bin}^{a} \quad \mathrm{Niu}$, Dawen ${ }^{*, a, b}$ \\ ( ${ }^{a}$ West China Hospital, Sichuan University, Chengdu 610041) \\ ( ${ }^{b}$ School of Chemical Engineering, Sichuan University, Chengdu 610041)
}

环丙烷类化合物不仅广泛地存在于药物和生物活 性分子中 $(\text { Scheme 1) })^{[1]}$, 同时环丙烷类化合物也可进行 多种官能团转化, 因此该类化合物在有机合成领域是一 种非常重要的合成子. 在复杂分子的合成和药物开发 中, 建立一种普适的方法构建手性的多官能团化环丙烷 类化合物非常重要 ${ }^{[2]}$.<smiles>CCC(C)C1C(=O)O[C@@H]1C(=O)N[C@H]1C[C@H]1CC(NC(=O)[OH2+])C(=O)O</smiles><smiles>O=C(O)c1cn(C2CC2)c2cc(N3CCNCC3)c(F)cc2c1=O</smiles><smiles>O=C(Nc1cc(Oc2cc(F)c(NC(=O)C3(C(=O)Nc4ccc(F)cc4)CC3)cc2F)ccn1)C1CC1</smiles>

图式 1 含环丙烷结构的生物活性分子

Scheme 1 Bioactive molecules containing cyclopropane

目前已经发展了多种合成手性环丙烷类化合物的 方法, 例如, 端烯的金属催化卡宾插入反应 ${ }^{[3]}$ 、烯丙醇和 高烯丙醇的 Simmons-Smith 环丙烷化反应 ${ }^{[4]}$ 以及活化烯 烃的共轭加成串联环化反应 ${ }^{[5]}$ 等. 虽然利用这些方法可 以高对映选择性地合成该类化合物, 但是也存在很多限 制, 比如卡宾插入与活化烯烃反应均需要带有吸电子基 团, Simmons-Smith 环丙烷化反应则需要存在导向基.
此外对映选择性环丙烯的氢烷基化制备手性环丙 烷衍生物是一种更为便捷的方法，该类反应可以在没有 特定导向基存在下, 通过单一转化得到一系列多取代的 环丙烷类化合物 ${ }^{[6]}$. 然而, 对映选择性的环丙烯类化合 物氢烷基化反应鲜有报道. Marek 课题组 ${ }^{[7]}$ 曾报道: 在铜 催化条件下利用有机金属试剂实现氢烷基化. 但底物范 围有一定的限制, 并且会产生化学计量的副产物.

中国科学院上海有机化学研究所孟繁柯课题组对 于钴催化的环丙烯对映选择性官能团化方面进行了深 入的研究, 2019 年该课题组 ${ }^{[8]}$ 利用钴催化实现环丙烯的 不对称氢烯基化反应. 近日该课题组报道了一例钴催化 的环丙烯不对称氢烷基化反应, 高立体选择性地构建了 一系列烷基取代的环丙烷类化合物(Scheme 2). 该方法 立体选择性优异、原子经济性好、使用的催化剂商业可 得、底物范围广泛.

2019 年, Yoshikai 课题组 ${ }^{[9]}$ 报道了一篇钴催化的立 体选择性环丙醇对氧杂桥环烯烃的加成反应，但是该反 应的底物范围仅限于氧杂桥环烯烃(Scheme 3).

受到该工作的启发, 作者设想在钴催化条件下, 环 丙醇开环产生的高烯醇钴物种可以对双键加成得到 $\beta$ 官能团化酮, 如果尝试将钴和环丙醇加入环丙烯中, 则 可得到含官能团的烷基多取代环丙烷. 在这个过程中他 们克服了三个困难: (1)底物的反应活性低, (2)对映选择 性低, (3) 高烯丙醇 $\beta$ - $\mathrm{H}$ 消除.

在反应条件篮选的过程中作者发现与以往的工作 不同，在该体系中甲醇和三乙撑二胺 $(\mathrm{DABCO})$ 是非必 要的, 但此时钴盐的抗衡离子对反应的立体选择性和产 率有明显影响. 在最优条件下作者考察了底物范围, 环

* Corresponding author. E-mail: niudawen@scu.edu.cn. Published online February 22, 2021. 


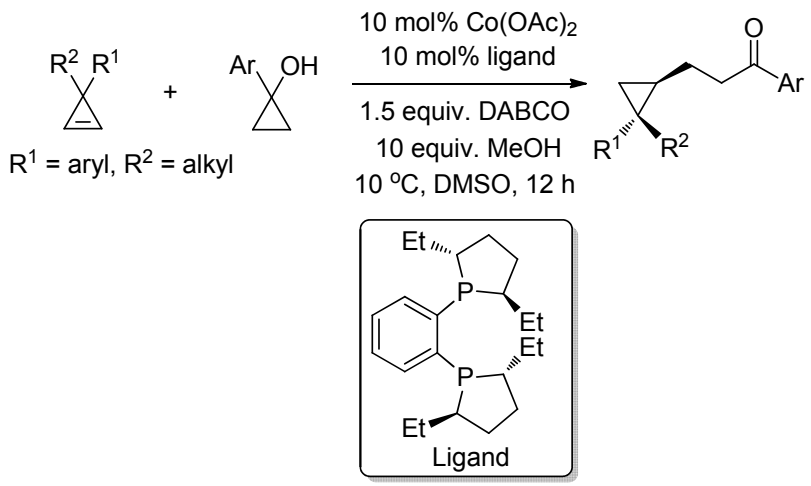

图式 2 钴催化的环丙烯不对称氢烷基化

Scheme 2 Cobalt-catalyzed asymmetric hydroalkylation of cyclopropenes

丙烯上不同电性的取代芳基、大位阻芳基以及杂芳基都 可以兼容, 环丙醇上不论是吸电子、富电子取代芳基、 杂芳基或是烯基均有高选择性和高收率.

值得一提的是, 环丙烷的 $\alpha$-酮酯类化合物是一类很 重要的合成中间体, 但是当环丙醇有吸电子酯基取代 时, 导致形成的高烯醇钴与羰基氧的配位能力下降, 会 降低高烯醇钴的反应活性, 作者通过调整碱、催化剂以 及甲醇的用量实现了含酯基取代类型的环丙醇底物, 这 对于生物活性分子的合成有重要意义(Scheme 4).

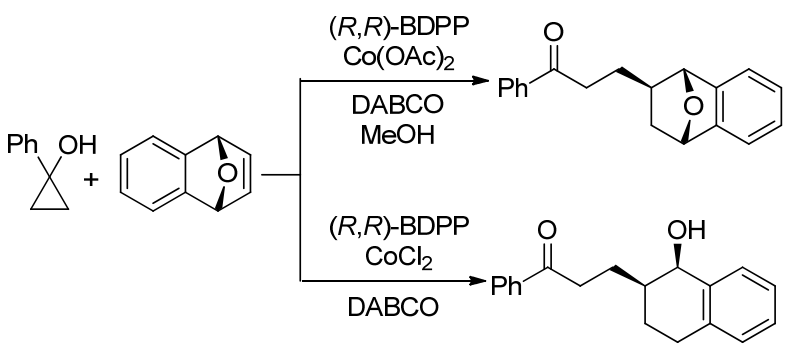

图 3 立体选择性环丙醇与氧杂桥环烯烃加成反应

Scheme 3 Enantioselective and chemodivergent addition of cyclopropanols to oxabicyclic alkenes

除此之外，作者还对该反应进行了一系列的衍生化 探究, 将得到的多取代环丙烷进行了各种官能团转化: 利用科里-巴克什一柴田(Corey-Bakshi-Shibata)立体选择 性还原酮到醇; 利用 Baeyer-Villiger 反应得到相应的 酯; 将 $\alpha$-酮酯类环丙烷化合物经氧化和胺化两步反应得 到胺. 为了探究该反应的机理，作者进行了氝代实验并 提出了可能的催化循环,他们认为质子转移步骤可能是 该反应的决速步骤(Scheme 5).

综上，孟繁柯课题组开发了第一例钴催化的非对映 和对映选择性构建烷基取代环丙烷类化合物的方法，该 方法选择性优异、原子经济性好、底物范围广、使用的 催化剂商业可得. 同时，作者也进行了衍生化研究并提 出了可能的机理.

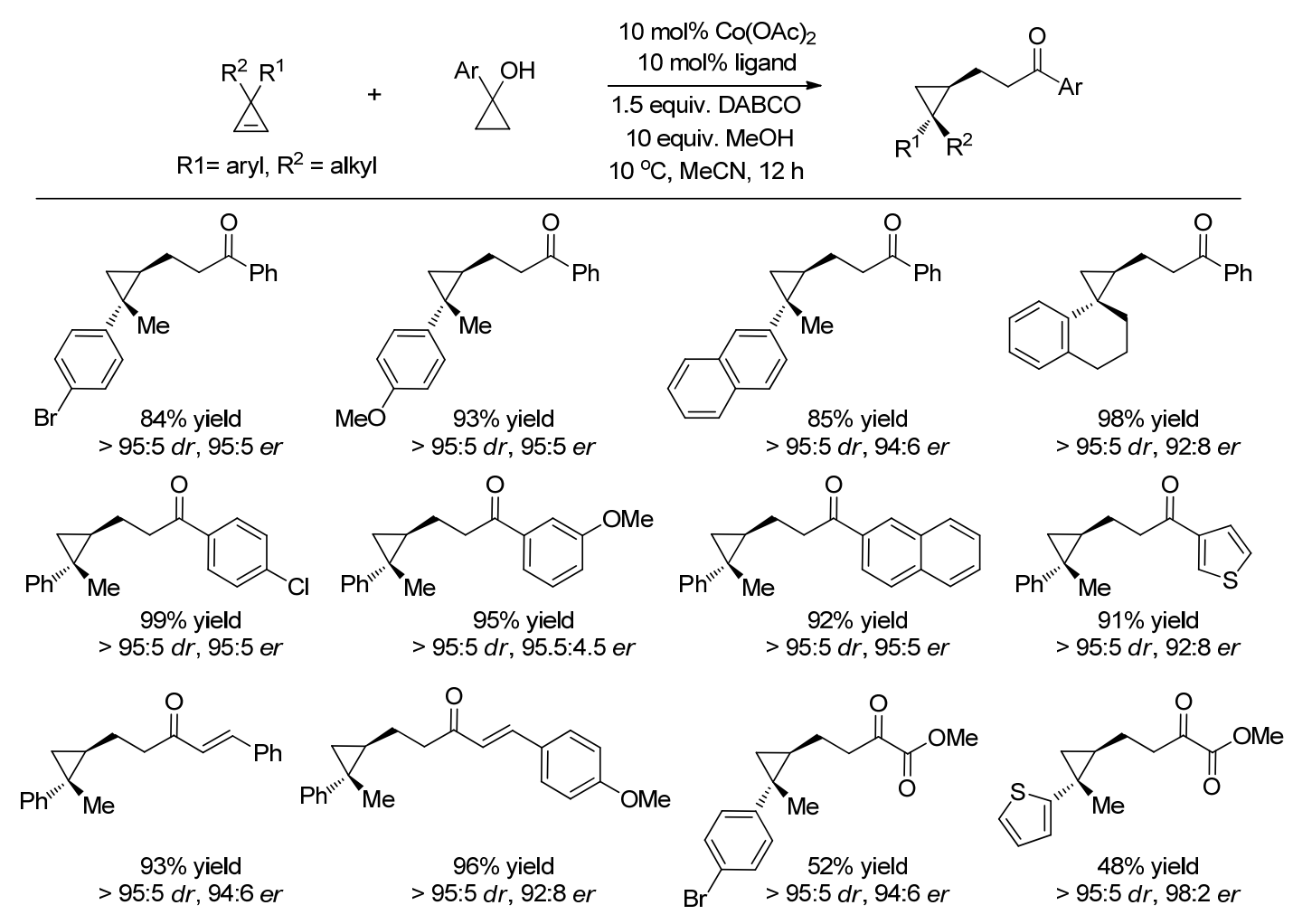

图 4 代表性底物实例

Scheme 4 Representative examples of substrate 


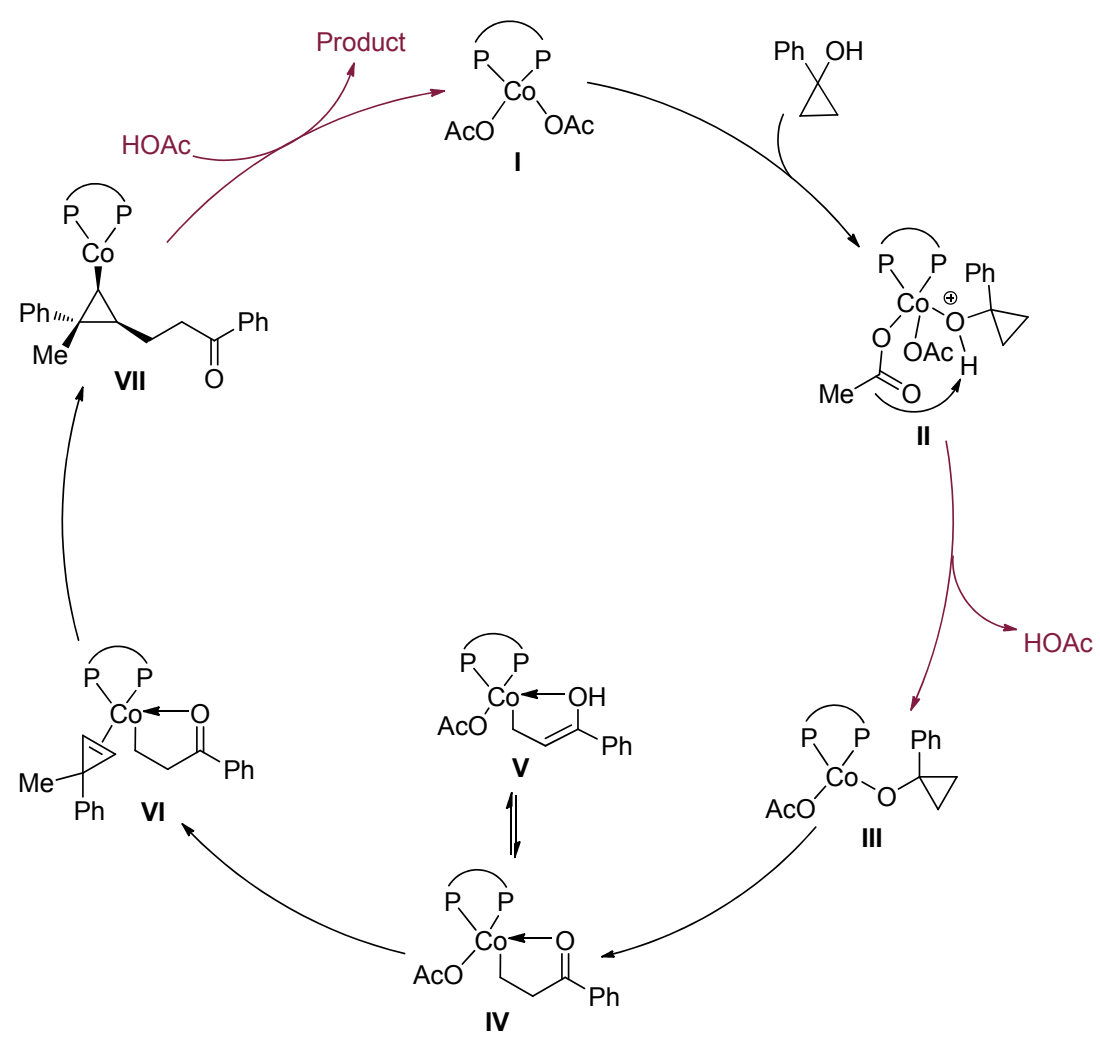

图 5 可能的催化循环

Scheme 5 Possible catalytic cycle

\section{References}

[1] Schneider, T. F.; Kaschel, J.; Werz, D. B. Angew. Chem., Int. Ed. 2014, 53, 5504.

[2] Vachharajani, N. N.; Yeleswaram, K.; Boulton, D. W. J. Pharm. Sci. 2003, 92,760

[3] Doyle, M. P.; Duffy, R.; Ratnikov, M.; Zhou, L. Chem. Rev. 2010, 110, 704 .
[4] Shitama, H.; Katsuki, T. Angew. Chem., Int. Ed. 2008, 47, 2450.

[5] Papageorgiou, C. D.; de Dios, M. A. C.; Ley, S. V.; Gaunt, M. J. Angew. Chem., Int. Ed. 2004, 43, 4641.

[6] Dian, L.; Marek, I. Chem. Rev. 2018, 118, 8415.

[7] Müller, D. S.; Marek, I. J. Am. Chem. Soc. 2015, 137, 15414.

[8] Zhang, H.; Huang, W.; Wang, T.; Meng, F. Angew. Chem., Int. Ed. 2019, 58, 11049.

[9] Yang, J.; Sekiguchi, Y.; Yoshikai, N. ACS Catal. 2019, 9, 5638.

(Cheng, F.) 